\title{
Different protein expression systems can influence the direction of the immune responses against $\mathrm{HCV}$ core protein in animal model
}

\author{
Mirnurollahi SM${ }^{1}$, Irani $S^{1}$, Davoudi $\mathbf{N}^{2}$, Bolhassani $\mathrm{A}^{3^{*}}$ \\ ${ }^{1}$ Department of Biology, Science and Research Branch, Islamic Azad University, Tehran, Iran. \\ ${ }^{2}$ Department of Biotechnology, Pasteur Institute of Iran, Tehran, Iran. \\ ${ }^{3}$ Department of Hepatitis and AIDS, Pasteur Institute of Iran, Tehran, Iran.
}

\begin{abstract}
Introduction: Hepatitis $C$ virus (HCV) infection is a major public health problem which influences about 170 million people worldwide. Different types of vaccines have been designed using HCV structural proteins to control the viral infection. The core nucleocapsid protein is one of the most conserved proteins and a desirable target for HCV vaccines, especially the protein-based vaccines. In current study, we generated the core protein recombinantly in prokaryotic (Escherichia coli) and eukaryotic (Leishmania tarentolae) expression systems and compared the humoral immune responses stimulated by each protein in a BALB/c mice model. Methods: The expression of HCV core protein was performed using the prokaryotic pET-28a/ BL21 expression system and also the eukaryotic LEXSY expression system. The recombinant core proteins expressed in E. coli and Leishmania were purified using reverse staining method and affinity chromatography under native conditions, respectively. The purified core proteins were detected by SDS-PAGE and Western blotting using anti-His antibody and were assessed by NanoDrop spectrophotometer. Finally, the abilities of both recombinant core proteins to induce the effective humoral immune responses were evaluated using indirect ELISA. Results: Our data indicated a clear band of $\sim 21 \mathrm{kDa}$ for the purified HCV core proteins in both expression systems, confirmed by SDS-PAGE and Western blotting. The mice immunization with both recombinant core proteins was able to produce high levels of antibody isotypes (IgG1 and IgG2a) in comparison with the controls $(p<0.05)$. In addition, the level of $\operatorname{IgG} 2$ a response was significantly higher in the group immunized with the core protein purified from leishmania compared to the protein generated from E. coli $(p<0.05)$. Conclusion: The recombinant core protein generated by the leishmania expression system could induce a Th1-biased immune response with respect to the increase of $\operatorname{IgG} 2$ a to $\operatorname{IgG} 1$ ratio.
\end{abstract}

KEYWORDS: Hepatitis $C$ virus, LEXSY expression system, E. coli expression system, Core, Humoral immune responses.

\section{INTRODUCTION}

The development of a safe and effective Hepatitis $C$ virus $(\mathrm{HCV})$ vaccine has attracted a special interest for prevention of other viral infections [1-6]. HCV belongs to the Flaviviridae family and has a positive single strand RNA in its genome [7, 8]. The HCV polyprotein is post-translationally divided into three structural proteins including the core nucleocapsid protein and the two envelope glycoproteins (E1 and E2) and seven nonstructural proteins (NS2, NS3, NS4A, NS4B, NS5A, NS5B and $\mathrm{P7}$ ) $[7,8]$. Among different $\mathrm{HCV}$ proteins, the core protein is a suitable target for development of $\mathrm{HCV}$ vaccines. It is

*Corresponding Author: Azam Bolhasani, Department of Hepatitis and AIDs, Pasteur Institute of Iran, Tehran, Iran.

Email: azam.bolhasani@yahoo.com, A_bolhasani@pasteur.ac.ir Tel/Fax: (+98) 2166969291 highly conserved among different HCV genotypes and is also a strong immunogen. Previous studies have indicated that HCV core protein generated in prokaryotic expression systems can be used to improve the screening assays [7]. Many studies have produced $\mathrm{HCV}$ core protein in different expression systems such as bacteria $[9,10]$, insects $[8,11,12]$, and yeast $[13,14]$. In recent years, the protozoan Leishmania tarentolae has been known as a novel eukaryotic expression system for generation of various recombinant proteins with special structures and functions [15]. In this expression system, a group of inducible or constitutive vectors have been designed to target the proteins of interest to intracellular compartments or for secretion. Furthermore, the strains expressing the recombinant proteins are shown to be stable, easy to culture and suitable for production in large scales [16]. In the current study, we 
generated $\mathrm{HCV}$ core protein in two expression systems of Escherichia coli and L. tarentolae. We subsequently evaluated and compared the resulted recombinant proteins for their ability to induce robust humoral immune responses in a BALB/c model. Our goal was to determine the effects of the abovementioned expression systems on the protein structure and folding associated with shifting of the humoral immune responses.

\section{MATERIALS and METHODS}

\section{Expression and purification of the $\mathrm{HCV}$ core protein in $E$. coli by reverse staining method}

The BL21 (DE3) bacterial strain harboring pET-core (Accession number: AB047640, [17]) was inoculated in $100 \mathrm{ml}$ TY2X medium and grown to an optical density of $0.7-0.8$ at $600 \mathrm{~nm}$. The expression of core protein was induced by adding $1 \mathrm{mM}$ IPTG and the pellet was harvested at $3 \mathrm{~h}$ post-induction. The bacterial pellets was dissolved in lysis buffer and placed on ice for $30 \mathrm{~min}$. The lysates were sonicated for $20 \mathrm{~min}$ and the samples were dissolved in sample buffer and boiled for $5 \mathrm{~min}$. The core proteins were analyzed by SDS-PAGE. An imidazoleSDS-Zn reverse staining method was used for the purification of the core protein as previously described [18]. The purified protein was concentrated and dialyzed against PBS (dialysis membrane, MWCO: $3.500 \mathrm{kDa}$ ). The protein concentration was assessed using NanoDrop spectrophotometer at $280 \mathrm{~nm}$. The recombinant protein was kept at $-20^{\circ} \mathrm{C}$ until use.

$\mathrm{HCV}$ core protein expression and purification in Leishmania by affinity chromatography using Ni-NTA column

The linearized pLEXSY-I-core plasmid ( $10 \mu \mathrm{g}$, previously provided to Hepatitis and AIDS Department, Pasteur Institute of Iran) was electroporated into $4 \times 107 \log$ phase parasites (T7-TR LEXSY host) in $2 \mathrm{~mm}$ cuvettes at $450 \mathrm{~V}$ and $500 \mu \mathrm{F}$ using Bio-Rad Gene PulserEcell. After two pulses, the recombinant stable transfectants were selected on M199-agar containing $50 \mu \mathrm{g} / \mathrm{ml}$ of bleomycin (Jena Bioscience, Germany). For genomic analysis, the recombinant clones were cultured in M199 media containing $50 \mu \mathrm{g} / \mathrm{ml}$ of bleomycin at $26^{\circ} \mathrm{C}$. The genomic DNAs were prepared by the DNeasy® Blood and Tissue Kit (GF-1). The integration of pLEXSY-I-core into the genome was performed by diagnostic PCR using the primer pairs (core forward/ core reverse) and also 5'odc forward/ utr1 (aprt) reverse primers according to Jena Bioscience manual. The recombinant T7-TR LEXSY host harboring the pLEXSYI-core was cultured in M199 media containing $50 \mu \mathrm{g} / \mathrm{ml}$ of bleomycin at $26^{\circ} \mathrm{C}$. The induction of the protein expression was performed by $10 \mu \mathrm{g} / \mathrm{ml}$ tetracycline in final concentration. For obtaining an optimal expression, different times of the cell harvest were checked (i.e., 24, 48 and $72 \mathrm{~h}$ ). The best time for the cell harvest was found to be $48 \mathrm{~h}$ after the induction. The expression of the core protein in Leishmania was confirmed by SDS-PAGE of the cell extracts. Finally, the recombinant core protein was purified by affinity chromatography on Ni-NTA resin column using 6xHis-tag, according to the manufacturer's instructions (Qiagen). The purification of the recombinant protein was done under native conditions and assessed using NanoDrop spectrophotometer at $280 \mathrm{~nm}$. The recombinant protein was kept at $-20^{\circ} \mathrm{C}$ until use.

\section{Western blot analysis}

The purified core proteins were analyzed using SDS-PAGE followed by staining with Coomassie brilliant blue as well as Western blotting. For the Western blot analysis, the core protein resolved on the gel was transferred onto protran nitrocellulose transfer membrane (Schleicher and Schuell Bioscience, Germany). The membrane was pre-equilibrated with TBST solution (10 mM Tris- $\mathrm{HCl}$ (pH 7.4), $150 \mathrm{mM} \mathrm{NaCl}$, and $0.1 \%$ Tween 20) containing $2.5 \%$ bovine serum albumin (BSA) overnight and then was incubated with anti-His antibody (1:10000, Qiagen) for $2 \mathrm{~h}$ at room temperature. After 3 washes with TBST, the membrane was incubated with anti-mouse IgGHRP (1: 10000, Sigma) for $1.5 \mathrm{~h}$ at room temperature. The immunoreactive protein bands were visualized using peroxidase substrate 3, 3'- Diaminobenzidine (DAB, Sigma).

\section{Mice immunization}

The immunization experiments were performed on female 6-8week-old BALB/c mice (Pasteur Institute of Iran, Tehran, Iran). The mice were maintained under specific pathogen-free conditions and were used under the guidelines of the Pasteur Institute Animal Care and Use Committee. Four groups of 5 mice were selected and immunized subcutaneously at the footpad. The groups 1 and 2 (G1 and G2) were injected 3 times with $10 \mu \mathrm{g}$ of the recombinant core protein purified from $E$. coli (B-core) plus Freund adjuvant (50:50 v/v), the recombinant core protein purified from Leishmania (L-core) plus Freund adjuvant (50: $50 \mathrm{v} / \mathrm{v})$, respectively. The control groups were injected with Freund adjuvant (G3) and PBS (G4). Table 1 shows the immunization regimens of the 4 groups.

\section{Antibody responses}

The mice groups were bled from retro-orbital at 3 and 6 weeks after the last immunization. The sera were then pooled for each group and stored at $-20{ }^{\circ} \mathrm{C}$ until use. The levels of IgG1 and IgG2a antibodies were measured by indirect ELISA. Briefly, 96-well flat-bottom ELISA plate (Greiner) were coated overnight at $4^{\circ} \mathrm{C}$ with the recombinant $\mathrm{HCV}$ core proteins (namely, the B-core and L-core; $10 \mu \mathrm{g} / \mathrm{ml}$ ) as an antigen diluted in PBS ( $\mathrm{pH}$ 7.2). The plates were then rinsed with washing buffer $(0.5 \%(\mathrm{v} / \mathrm{v})$ Tween-20 in PBS) and were incubated with blocking buffer (1\% BSA in PBS) for $2 \mathrm{~h}$ at 37 ${ }^{\circ} \mathrm{C}$. The diluted pooed sera (1:50 in dilution buffer $0.5 \%(\mathrm{v} / \mathrm{v})$ Tween-20 in blocking buffer), were added to the plates which were incubated for $2 \mathrm{~h}$ at $37{ }^{\circ} \mathrm{C}$. After rinsing with washing buffer, the plates were incubated with biotin-conjugated goat anti-mouse IgG1 or IgG2a (diluted 1:1000 in 1\% BSA/PBSTween, Southern biotechnology Association Inc, USA) for $2 \mathrm{~h}$ at $37^{\circ} \mathrm{C}$. The plates were washed and incubated with streptavidin-horseradish peroxidase diluted in PBS (1:10000; Sigma) at $37^{\circ} \mathrm{C}$ for $1 \mathrm{~h}$. The detection was performed with 100 $\mu \mathrm{l}$ of O-Phenylenediamine (OPD, Sigma) as the substrate in citrate phosphate buffer ( $\mathrm{pH} 4.5)$, followed by incubation for 30 min at $37^{\circ} \mathrm{C}$. The enzyme reaction was stopped by $1 \mathrm{M} \mathrm{H} 2 \mathrm{SO} 4$ and the absorbance was measured at $492 \mathrm{~nm}$.

\section{Statistical analysis}

The differences in the levels of antibody responses between the control and the test groups were determined by one-way ANOVA (GraphPad Prism version 5.0 software). Such differences were considered statistically significant when the $\mathrm{p}$ value was $<0.05$. 
Table 1. Mice immunization using the recombinant core proteins generated in E.coli (B-core) and Leishmania (L-core)

\begin{tabular}{|c|c|c|c|c|}
\hline Groups & Regimen & Day 0 & Day 14 & Day 28 \\
\hline G1 & Protein + adjuvant & $\begin{array}{c}\text { B-core protein }+ \\
\text { complete Freund }\end{array}$ & $\begin{array}{c}\text { B-core protein }+ \\
\text { incomplete Freund }\end{array}$ & $\begin{array}{c}\text { B-core protein }+ \\
\text { incomplete Freund }\end{array}$ \\
\hline G2 & Protein + adjuvant & $\begin{array}{c}\text { L-core protein }+ \\
\text { complete Freund }\end{array}$ & $\begin{array}{c}\text { L-core protein }+ \\
\text { incomplete Freund }\end{array}$ & $\begin{array}{c}\text { L-core protein }+ \\
\text { incomplete Freund }\end{array}$ \\
\hline G3 & Control & $\begin{array}{c}\text { complete Freund } \\
\text { adjuvant }\end{array}$ & $\begin{array}{c}\text { incomplete Freund } \\
\text { adjuvant }\end{array}$ & $\begin{array}{c}\text { incomplete Freund } \\
\text { adjuvant }\end{array}$ \\
\hline G4 & Control & PBS & PBS & PBS \\
\hline
\end{tabular}

\section{RESULTS}

\section{Confirmation of B-core and L-core in SDS-PAGE and Western blotting}

Our data showed a dominant band of $\sim 21 \mathrm{kDa}$ for the recombinant core proteins expressed in both E. coli and Leishmania expression systems. The integration of the core gene in the genomic DNA of the recombinant Leishmania promastigotes was confirmed by PCR analysis. The expected $1100 \mathrm{bp}$ band was only observed from the transformed cells indicating the correct integration of the expression constructs into the odc locus. The expected PCR product of the core was appeared as a $573 \mathrm{bp}$ fragment for the core positive clones. The best time for the expression of the core was determined at $48 \mathrm{~h}$ after the induction by tetracycline. Immobilized metal-affinity chromatography (IMAC) was applied to purify the recombinant core protein in LEXSY expression system. This method was based on the interaction between a transition metal ion (e.g., $\mathrm{Ni}$ $2+)$ immobilized on a matrix and specific amino acid side chains (e.g., Histidine). Indeed, the core protein containing polyhistidine sequences (His-tag) was significantly purified by the affinity chromatography under native conditions (i.e., 300 $\mathrm{mM}$ Imidazole). However, the reverse staining method based on Zn-Imidazole-SDS was more efficient than affinity chromatography for purification of the full length core protein in E. coli expression system. Both purified core proteins migrated as a $\sim 21 \mathrm{kDa}$ protein in SDS-PAGE. Western blot analysis was performed using anti-His antibody to ensure the proper expression of the recombinant core protein. Specific bands with the expected size $(\sim 21 \mathrm{kDa})$ were detected in the blots of the purified proteins from both systems (Fig. 1).

Stimulation of serum antibody response by protein-based immunizations through subcutaneous administration We evaluated the potency of the two purified core proteins (Bcore and L-core) for induction of humoral immune responses in a mice model. As shown in Fig. 2, all the mice receiving B-core and L-core developed significantly core-specific IgG1 and
IgG2a immune responses as compared to the control groups (G3 and G4, $p<0.05$ ). The ratio of IgG2a:IgG1 is a useful indication to compare the relative Th-bias between the groups. The humoral immune responses in the group which was immunized with L-core (G2) were directed toward IgG2a induction in comparison with the control groups, similar to the group immunized with B-core $(\mathrm{G} 1)$. In contrast, the IgG1/IgG2a ratio was significantly increased in the group immunized with B-core (G1) as compared to the other groups $(p<0.05)$. In mice, the presence of $\operatorname{IgG} 2 \mathrm{a}$ antibodies is an indicative of a Th1-biased response since the Th1 cytokines are necessary for this isotype shifting in the B cells. As described in Fig. 2, the group immunized with L-core elicited a Th1-biased immune response with respect to the increase of $\operatorname{IgG} 2 \mathrm{a} / \mathrm{IgG} 1$ ratio in contrast to the group immunized with B-core which induced a Th2-biased immune response. All the members of the immunized groups did not show any sign of suffering from toxicity and remained healthy. In addition, the humoral immune responses were stable at the sixth week after the last immunization.

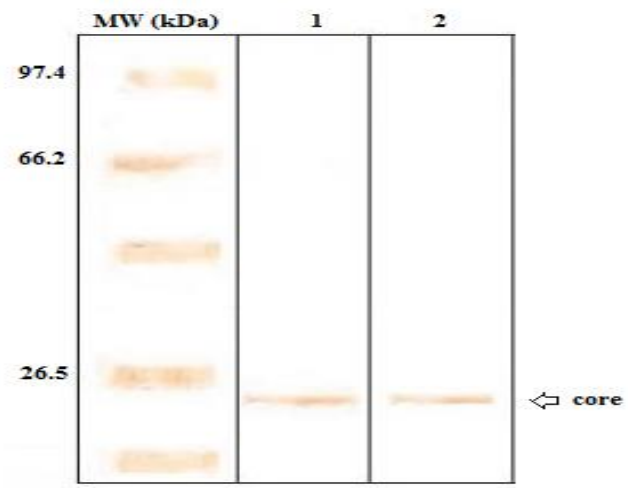

Fig. 1. Identification of core proteins by Western blotting using anti-His antibody: Lane 1: B-core, Lane 2: L-core. The weight of the molecular mass markers (Premixed protein molecular weight marker: 14.4-97.4 kDa) is indicated as MW.
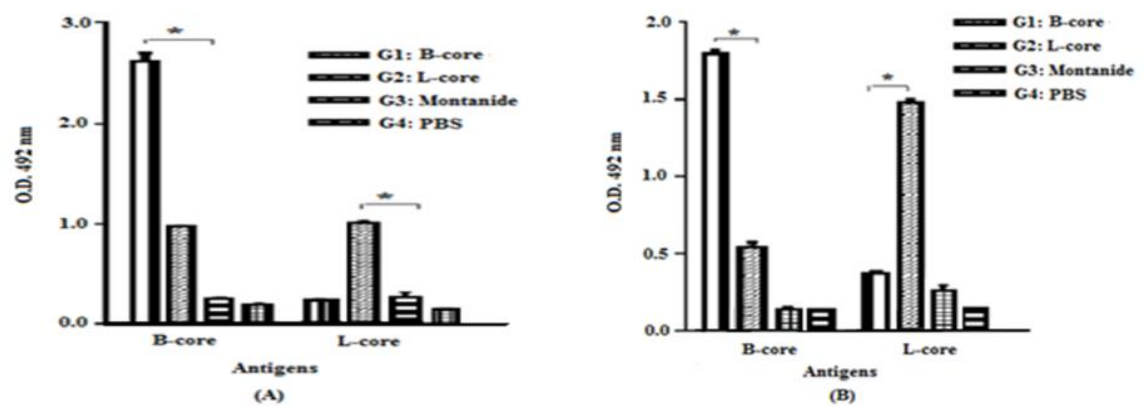

Fig. 2. Analysis of $\operatorname{IgG1}(\mathrm{A})$ and $\operatorname{IgG} 2 \mathrm{a}(\mathrm{B})$ antibody levels with respect to the coated antigens (B-core and L-core) using ELISA at 3 weeks after the third immunization. Data shows antibody responses of the pooled mice sera with independent experiments. The error bars indicate mean \pm SD $* p<0.05$ ). 


\section{DISCUSSION}

HCV core antigen is a highly conserved protein and a major target to develope HCV preventive vaccines [19]. The generation of the core protein has been attempted in various expression systems $[9,10,12-14]$. In this regard, the bacterial expression systems possess several advantages including less time of production, high-level yields and cost-effectiveness as compared to other eukaryotic systems that use insect cells or yeasts [7]. For example, the expression of HCV core in E. coli BL21 using pGEX4T-2 expression vector has been performed using IPTG inducer as a recombinant fusion protein (e.g., GSTcore). In these studies, HCV core has been purified through affinity chromatography [7]. This method required further isolation and purification processes. In the current study, pET28a/BL21 bacterial system was used for the core protein expression. The core protein migrated as a $\sim 21 \mathrm{kDa}$ protein during the electrophoresis. In addition, the purification of the recombinant core protein was performed using reverse staining method.

On the other hand, Leishmania (LEXSY) expression system has been used as an alternative to other eukaryotic systems because of its simple genetic manipulation, suitable protein folding and low-cost of production [20]. For example, Laminin (LM)-332, a large heterotrimeric glycoprotein, produced in L. tarentolae has shown similar cell adhesion activity to LM-332 which was purified from mammalian cells, indicating its proper folding and assembly [21]. Moreover, this system is suitable to express recombinant proteins with a tag, allowing easy purification and detection of the recombinant protein [22]. Herein, LEXSY system was used to express the recombinant HCV core protein with a $6 \mathrm{X}$-His-tag. Our results indicated the great benefit of the established L. tarentolae for production of the recombinant core protein. A $\sim 21 \mathrm{kDa}$ protein band was detected by SDS-PAGE and Western blotting, similar to that in the bacterial system. We then evaluated the humoral immune responses against the purified core proteins in both systems. The results showed that the adjuvanted core proteins generated in both systems induced a statistically significant increase of serum anti-core $\operatorname{IgG} 2 \mathrm{a}$ and IgG1 isotypes as compared to the control groups. Based on our results, the core protein produced in Leishmania system could increase the shifting of the humoral immune responses toward IgG2a. In contrast, the core protein generated in the bacterial system could enhance the shifting of the humoral immune responses toward $\mathrm{IgG1}$. Indeed, $\mathrm{HCV}$ core protein generated in the Leishmania expression system indicated a Th1-type response with respect to high $\mathrm{IgG} 2 \mathrm{a} / \mathrm{IgG} 1$ ratio as compared to $\mathrm{HCV}$ core protein generated in the bacterial system. Meanwhile, there was no severe reaction at the injection sites after the core protein-based immunizations. Briefly, these data indicated that the alteration of the structure and folding are likely effective parameters in switching of the antibody responses.

\section{ACKNOWLEDGEMENT}

This project was funded with support from the Pasteur Institute of Iran (Grant No. 689). We would like to acknowledge Fatemeh Motevalli and Elnaz Agi for their assistance in performing the experiments.

\section{CONFLICT OF INTEREST}

The authors declare that they have no conflict of interest.

\section{REFERENCES}

1. Deng L, Ma L, Virata-Theimer ML, Zhong L, Yan H, Zhao Z et al. Discrete conformations of epitope II on the hepatitis $\mathrm{C}$ virus $\mathrm{E} 2$ protein for antibody-mediated neutralization and nonneutralization. Proceedings of the National Academy of Sciences of the United States of America. 2014;111(29):10690-5. doi:10.1073/pnas.1411317111.

2. Torresi J, Johnson D, Wedemeyer H. Progress in the development of preventive and therapeutic vaccines for hepatitis $\mathrm{C}$ virus. Journal of hepatology. 2011;54(6):1273-85. doi:10.1016/j.jhep.2010.09.040.

3. Gummow J, Li Y, Yu W, Garrod T, Wijesundara D, Brennan AJ et al. A Multiantigenic DNA Vaccine That Induces Broad Hepatitis C VirusSpecific T-Cell Responses in Mice. Journal of virology. 2015;89(15):79918002. doi:10.1128/JVI.00803-15.

4. Alekseeva E, Sominskaya I, Skrastina D, Egorova I, Starodubova E, Kushners E et al. Enhancement of the expression of HCV core gene does not enhance core-specific immune response in DNA immunization: advantages of the heterologous DNA prime, protein boost immunization regimen. Genetic vaccines and therapy. 2009;7:7. doi:10.1186/1479-05567-7.

5. Chmielewska AM, Naddeo M, Capone S, Ammendola V, Hu K, Meredith $\mathrm{L}$ et al. Combined adenovirus vector and hepatitis $\mathrm{C}$ virus envelope protein prime-boost regimen elicits $\mathrm{T}$ cell and neutralizing antibody immune responses. Journal of virology. 2014;88(10):5502-10. doi:10.1128/JVI.03574-13.

6. Wada T, Kohara M, Yasutomi Y. DNA vaccine expressing the nonstructural proteins of hepatitis $\mathrm{C}$ virus diminishes the expression of $\mathrm{HCV}$ proteins in a mouse model. Vaccine. 2013;31(50):5968-74. doi:10.1016/j.vaccine.2013.10.037.

7. Yousaf MZ, Idrees M, Saleem Z, Rehman IU, Ali M. Expression of core antigen of HCV genotype $3 \mathrm{a}$ and its evaluation as screening agent for HCV infection in Pakistan. Virology journal. 2011;8:364. doi:10.1186/1743422X-8-364.

8. Baumert TF, Ito S, Wong DT, Liang TJ. Hepatitis $\mathrm{C}$ virus structural proteins assemble into virus like particles in insect cells, Journal of Virology. 1998;72(5):3827-36.

9. Hemmat JYB, Khajeh KH, Moosavi-Movahedi AA, Karkhane AA. Over-expression of full-length core protein of hepatitis $\mathrm{C}$ virus by Escherichia coli cultivated in stirred tank fermentor, Iran J Biotechnol. 2011;9:245-52.

10. Linbai Ye JG, Xiaolin M, Jinping Xu, Ying Z, Min H, Lei M. Expression of $\mathrm{E} 1$ gene of a hepatitis $\mathrm{C}$ virus in $E$. coli and protein purification, J Nat Sci. 1996;1:279-82.

11. Yazdani-Neyshabouri AM, Jahanian Najafabadi A, Bouzari S, Arashkia A, Sadat SM, Siadat SD, et al. Expression of recombinant hepatitis C virus (HCV) Core, E1 and E2 proteins by the baculovirus expression vector system, African Journal of Microbiology. 2012;6:4152-7.

12. Choi SH, Kim SY, Park KJ, Kim YJ, Hwang SB. Hepatitis C virus core protein is efficiently released into the culture medium in insect cells. Journal of biochemistry and molecular biology. 2004;37(6):735-40.

13. Fazlalipour MKH, Monavari SHR, Mollaie HR. Recombinant core-e1e2 protein expressed in Pichia pastoris yeast, a candidate vaccine for hepatitis C virus. Antiviral Antiretrovir. 2014;6:139-47.

14. Donato GMRN, Grillo JM, Musacchio A, Vina A, Alvarez C, Figueroa $\mathrm{N}$, et al. Expression and processing of hepatitis $C$ virus structural proteins in Pichia pastoris yeast. Biochemical and Biophysical. 2006;342:625-31.

15. Fernandez-Robledo JA, Vasta GR. Production of recombinant proteins from protozoan parasites. Trends in parasitology. 2010;26(5):244-54. doi:10.1016/j.pt.2010.02.004.

16. Niimi $T_{2}$ Recombinant protein production in the eukaryotic protozoan parasite Leishmania tarentolae: a review, Methods Mol. Biol. 2012;824:307-15.

17. Mirnurollahi SM, Bolhassani A, Irani Sh, Davoudi N, Expression and purification of $\mathrm{HCV}$ core and core-E1E2 proteins in different bacterial strains, Iran J Biotech. 2015; 13(2): e1249.

18. Simpson RJ. Zinc/Imidazole procedure for visualization of proteins in gels by negative staining. CSH protocols. 2007;2007:pdb prot4701. doi:10.1101/pdb.prot4701.

19. Torbati E, Bandehpour M, Pakzad P, Mosaffa N, Koochaki A, Kazemi $B$. The evaluation of hepatitis $C$ virus core antigen in immunized BALB/c 
mice. Hepatitis monthly. 2012;12(6):391-7. doi:10.5812/hepatmon.6141. 20. Sillanpää M, Melén K, Porkka P, Fagerlund R, Nevalainen K, Lappalainen M, et al, Hepatitis C virus core, NS3, NS4B and NS5A are the major immunogenic proteins in humoral immunity in chronic $\mathrm{HCV}$ infection, Virology Journal. 2009;6:1-12.

21. Basile G, Peticca M. Recombinant protein expression in Leishmania tarentolae. Molecular biotechnology.

$2009 ; 43(3): 273-8$ doi:10.1007/s12033-009-9213-5.

22. Phan HP, Sugino M, Niimi T. The production of recombinant human laminin-332 in a Leishmania tarentolae expression system. Protein expression and purification. 2009;68(1):79-84 doi:10.1016/j.pep.2009.07.005. 